\title{
The Effect of Unmet Expectations of Information Quality on Post-Acceptance Workarounds among Healthcare Providers
}

\author{
Karoly Bozan \\ Duquesne University \\ bozank@duq.edu
}

\author{
Andrew Berger \\ Care Alliance Health Center \\ aberger@carealliance.org
}

\begin{abstract}
Electronic health record (EHR) systems have the capacity to aid clinical decision making by providing timely and relevant information about patients. However, providers' lack of access to complete and upto-date information in the required format hinders their ability to make timely decisions and often leads to misdiagnosis or redundant, duplicate tests. This research evaluates the extent to which pre-adoption information quality expectations are met and their effect on post-adoption satisfaction with an EHR system in terms of information quality and the workarounds that they may generate. The hypotheses were empirically tested through analysis of the responses of 64 healthcare stakeholders. The results indicate that lower information quality was perceived post-adoption than was expected at pre-adoption of the EHR system. Ultimately, workarounds were found largely to be a direct result of dissatisfaction with the EHR system. The results have implications for remedies to workarounds in terms of policy, training, and EHR system features modifications.
\end{abstract}

\section{Introduction and Motivation for the Study}

The patient safety literature highlights the importance of electronic patient information, and provider access to patient information is vital for establishing proper diagnosis and making decisions in regard to appropriate treatment [1]. Healthcare providers, including physicians and nurses, depend on the ability to obtain such information from widely adopted health information systems. Healthcare institutions, including provider offices and hospitals, have made significant progress toward implementing patient information management software with a wide range of functionalities in their practices [2].

Implementation of a successful health information system (HIS), such as an electronic health record (EHR) system, depends on its ability to meet complex system, organizational-, and user-level requirements [3]. Providers in the United States received financial incentives to implement and properly use certified EHR systems, and other developed countries also implement advanced HIS [4]. EHR is defined as a repository of longitudinal patient information in digital form, stored and exchanged securely, and accessible by multiple authorized users. It contains retrospective, concurrent, and prospective information and its primary purpose is to support continuing, efficient and quality integrated health care $[5$ p.2].

Stakeholders of an EHR system range from providers to administrator and patients and they use EHR systems both in smaller provider offices and larger hospitals [6]. Healthcare providers rely on the information the EHR system provides to them in addition of patient input, if possible, for proper diagnosis and treatment plan.

Obtaining timely and relevant information regarding patients' current and historical health status can be challenging when there is decentralized data across providers' information systems or even paper records. Lack of timely and relevant information has been found to be one of the leading causes of re-hospitalization, duplicate tests, complications due to misdiagnosis or improper treatment plan, and increased cost of patient care $[8,9]$.

Research also has found that computer workarounds can jeopardize the safety of patients and the confidentiality of their data [10]. Workarounds are a "post-implementation phenomenon widespread in organizations. They are commonly defined as noncompliant user behaviors vis-à-vis the intended system design, which may go so far as to bypass the formal systems entirely" [11 p.264]. A workaround, in the context of this study, is defined as the informal and temporary or permanent practices for handling systematic, organizational, or policy-driven exceptions to normal workflow to reach a desired goal during patient care. Healthcare providers may work around the medical information system for variety of reasons, such as saving time [12], addressing poor fitting workflow design [13], compensating for system shortcomings [14] and not finding the information provided sufficient [15]. Furthermore, workarounds in healthcare also threaten the implementation success of an EHR system and hinders the work of other stakeholders $[16,17]$.

Prior to the implementation or upgrade of an information system, users form an expectation about the system's capabilities as related to their work functions [15]. Healthcare providers, including physicians and 
nurses, depend on and, thus, may expect comprehensive, timely, and up-to-date data available in a required format that is relevant to patient visits [18]. In this regard, the study is guided by the following research questions, which will guide the hypotheses (presented later in this paper): To what extent are healthcare providers' pre-adoption information quality expectations met? What is the effect of post-adoption dissatisfaction with the EHR system in terms of information quality on the use of workarounds to overcome the perceived information quality shortcomings?

\section{Theoretical Background}

There are numerous theories and models related to user acceptance of information systems, for which usage is the dependent variable [19-22]. The extent an information system is used as intended is affected by organizational workflows, internal and external policies, system capabilities, and technology-task fit among other variables. Thus, actual usage is a major indicator of system implementation success. Information systems, by definition, are a network of technology, people, and processes that capture, transmit, manipulate, or display information to support people, organizations, or other software systems [23]. As such, the quality of information is fundamental for the proper, effective, and efficient use of an information system.

As noted, this study investigates the information quality expectations of healthcare providers for their EHR system and the extent to which the system circumvented when expectations are not met. Unmet expectations may affect providers' satisfaction with the EHR system in terms of information quality and trigger possible workarounds to achieve the desired goal of treating patients. Healthcare providers' information quality expectations and the workarounds they may trigger are viewed through the lenses of the following models:

\section{- Delone and McLean Information System Success Model [24] \\ - $\quad$ Expectation-Disconfirmation Theory [25] \\ - $\quad$ Theory of Workarounds [26]}

\subsection{Delone and McLean Information System Success Model}

Delone and Mclean in 1992 [24] reviewed information system (IS) success definitions and their measures and divided them into six categories. They then reviewed their model ten years later [27,28], considering other contributions, and updated the six categories into: information quality, system quality, service quality, intention to use, user satisfaction, and net benefits. For the purposes of our study, we focus on information quality and its effect on user satisfaction. User satisfaction is the most widely used measure for IS success for three reasons: (1) it has a high degree of face validity; (2) the numerous studies allowed the development of reliable items for measuring satisfaction with IS; and (3) satisfaction as a measure of success is stronger than other measures of success [24]. The definitions of satisfaction in the IS literature include psychological processes, beliefs, feelings, and attitudes in regard to user experience and the sum of feelings and attitudes in regard to certain factors that affect user experience positively or negatively [29]. In this study, user satisfaction with IS information quality is defined as a healthcare provider's belief that the EHR system provides timely and relevant data in the format needed and from reliable sources to aid in decision making in the patient care process.

Information quality has always been a critical concern of organizations and receives increasing attention in IS research. Recently, due to the growth of data available from various sources and storage in data warehouses, high-quality data have become the focus of practitioners and academia. Further, studies have suggested the need to define the more granular dimensions of information quality that include service and product quality, as information is considered both a product and a service [30]. This study adopted the four main information quality categories from Wang and Strong that capture the requirement for high-quality information to be "intrinsically good, contextually appropriate for the task, clearly represented, and accessible to the data consumer" (p. 22) and that provide the foundation to measure user satisfaction of the EHR system in terms of information quality.

\subsection{Expectation-Disconfirmation Theory}

Expectation-Disconfirmation Theory (EDT) has been widely used in the consumer behavior literature to study consumer satisfaction and post-purchase behavior, such as repurchase or disappointment in the product $[31,32]$. The EDT framework posits that consumers initially form an expectation of a specific product or service prior to purchase. After accepting and using the product or service for a period of time, they form a perception of its performance. This perception may or may not meet their initial expectation, which will affect their satisfaction and repurchase intention of the product or service. Oliver also proposed a widely used simplified expectation-disconfirmation model in 1997 [33]. In this model, the expectations are theorized to have a negative influence on disconfirmation, as higher expectations are more likely to result in negative disconfirmation. Both expectations and 
disconfirmations are predicted to lead to higher satisfaction levels, without including performance as a mediator variable in regard to satisfaction.

In terms of this study, healthcare providers form an expectation about the EHR system information quality prior to using it. The expectation of information quality is based on user needs to effectively and efficiently perform their job duties. After using the EHR system, providers may or may not disconfirm their initial expectations, which will, accordingly, affect their satisfaction with the EHR system in terms of information quality. Positive disconfirmation is hypothesized to result in better than expected information quality, while negative disconfirmation is hypothesized to result in lower information quality than expected [33]. This study follows the simplified EDT model, as providers do not select an EHR system based on their expected performance level on information quality; further, performance is beyond the scope of this study.

\subsection{Theory of Workarounds}

Workarounds have been viewed as the activities involved in overcoming an obstacle to attain a goal [26]. The obstacle may be shortcomings in the system or workflow, but training and policies also can affect the way that users ultimately use an IS. Although users may create a quicker or more efficient way of using the system, generally, workarounds are considered hazardous and opportunistic, noncompliant behavior that undermines management intentions [34]. In the healthcare context and the information quality domain, workarounds are generally triggered by shortcomings of the EHR system's ability to capture or provide the needed information $[35,36]$ among responses to operational failures and workflow restraints [37,38]. When the required patient information is not available as an output or the information cannot be properly captured as an input, users may create workarounds. For example, they may access information from a legacy system or paper records. Similarly, they may use an alternative field for capturing relevant data that the system is not configured to capture and store, therefore, it will not be properly displayed in the appropriate context for decision making. The literature identifies positive and negative outcomes of workarounds that affect patients, providers, and healthcare organizations. For example, workarounds may reduce the stress of dealing with the EHR system and better meet patient needs; these workarounds can include such items as enabling earlier medication administration [39] and circumventing workflow or system barriers to delivering care $[11,40]$. Nevertheless, the negative outcomes of workarounds are seen in patient exposure to safety risks [41,42], loss of patient data [43], hindering of organizational learning and improvement [11], and increasing the cognitive effort and time needed to use the system [42].

\section{Research Model and Hypotheses}

This research is guided by simplified EDT, the IS success model, and workaround theory in its examination of the role of met or unmet expectations of information quality to predict satisfaction and its effect on workaround of the EHR system. The study proposes four casual paths: expected information quality (EIQ) to satisfaction (SA), EIQ to disconfirmation (DC), DC to $\mathrm{SA}$, and SA to workaround (WA). Figure 1 depicts the proposed model and hypotheses, with their direction of effects.

\subsection{Research Model}

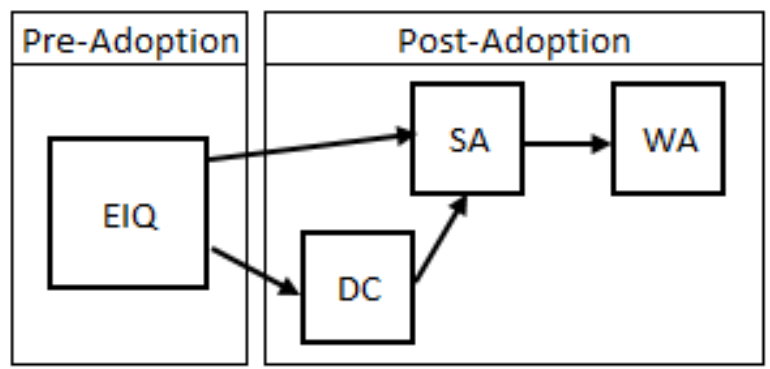

Figure 1. Proposed model and hypotheses.

The one-dimensional conceptualization of provider satisfaction is derived from underlying information quality expectations that are positively or negatively disconfirmed and lead to providers' workaround of an EHR system in terms of information quality. EIQ is a latent, formative, second-order construct that is measured by four categories of data-quality categories defined by Wang and Strong [44] and summarized in Table 1:

(1) intrinsic: the quality of data in their own right and consists of accuracy, believability, objectivity, and reputation of the source dimensions;

(2) contextual: information quality within the context of the task at hand and consists of value-added, relevancy, timeliness, completeness, and amount of data dimensions;

(3) representational: information quality in terms of representation and delivery of data and consists of interpretability, ease of understanding, representational consistency, and concise representation dimensions;

(4) accessibility: the capability of the information system to provide data and consists of accessibility, ease of use, operations, and security dimensions.

The dimensions provide comprehensive coverage of the multidimensional informaton quality construct [30]. 


\begin{tabular}{|l|l|}
\hline Category & Dimensions \\
\hline Intrinsic & $\begin{array}{l}\text { accuracy, believability, } \\
\text { objectivity, reputation of the } \\
\text { source }\end{array}$ \\
\hline Contextual & $\begin{array}{l}\text { value-added, relevancy, } \\
\text { timeliness, completeness, } \\
\text { amount of data }\end{array}$ \\
\hline Representational & $\begin{array}{l}\text { interpretability, } \\
\text { ease of understanding, } \\
\text { representational consistency, } \\
\text { concise representation }\end{array}$ \\
\hline Accessibility & $\begin{array}{l}\text { accessibility, ease of use, } \\
\text { operations, security }\end{array}$ \\
\hline
\end{tabular}

Table 1. Information quality categories and dimensions

The pre-adoption part of the model is designed to measure the initial, healthcare provider pre-use information quality expectations. Then, after twomonths of use of the EHR system, providers disconfirm the initial information quality expectations, which results in positive or negative disconfirmation. The disconfirmation outcome may influence the satisfaction with the EHR system in terms of information quality and it can influence the extent of workaround of the EHR system.

\subsection{Hypotheses}

The hypotheses in this study build on the above covered theories and related literature in the healthcare context. Integrating information quality into EDT and the IS success model are providing the base of $\mathrm{H} 1-\mathrm{H} 3$, in which disconfirmation of the information quality expectation affect satisfaction with an EHR system in terms of information quality. $\mathrm{H} 4$ build on the workaround theory and posits that satisfaction with an EHR system in terms of information quality is negatively correlated to the extent healthcare providers work around the system to overcome information quality shortcomings. Justification of the hypotheses follows.

To properly diagnose and treat patients, healthcare providers need access to timely, accurate, and relevant data that come from a reliable source and are easy to interpret. Providers have expectations for quality information from their EHR system, which form their beliefs and attitudes in regard to the system [50-52]. The information quality dimension is considered an objectbased belief, and satisfaction with the EHR system is considered an object-based attitude $[45,46]$. Information that the EHR system produces is considered an output while the information it captures is considered an input. The perception of satisfaction with an EHR system increases with the perception of quality information input and output [47-49]. Physicians often come to an EHR system with precise information need affected by patient characteristics and clinical situations. Providers indicate higher satisfaction with an EHR system that provides relevant information to their needs in a usable format from a reliable source. Hence, it is proposed:

$H_{1}$ : Pre-adoption expectations of information quality are positively associated with healthcare providers' satisfaction with the EHR system.

Disconfirmation is the discrepancy between the anticipated or expected quality of the good or service and the quality that was actually received or experienced [32]. This discrepancy is positive when the actual experience is better than expected or negative when the actual experience is worse than expected [50,53,54]. Following the notion of EDT, healthcare providers have certain initial expectation levels for the information quality that their EHR system provides. If these initial expectations are not met once they use the EHR system, negative disconfirmation results. Healthcare providers have high quality expectations for the dimensions of information that they need the most to execute a proper diagnosis and treatment plan [50]. The higher the expectations, the more likely the EHR system will fall short in delivering them, and negative disconfirmation will result and decrease satisfaction with the EHR system. Conversely, positive disconfirmation occurs when the EHR system outperforms the initial expectations of information quality and results in increased satisfaction with the EHR system. This is due to the disconfirmation effect that has been well studied in the IS literature [53,55-57]. Therefore, it is posited:

$\mathrm{H}_{2}$ : Pre-adoption expectations of information quality are negatively associated with healthcare providers' post-adoption disconfirmation of the initial information quality expectations.

Studies in the consumer behavior literature investigated the causes and formation process of satisfaction through EDT [58,59]. The EDT suggests that the user satisfaction is determined by the size and direction of the discrepancy between expectation and its disconfirmation. On the basis of this disconfirmation and the EDT, it is believed that disconfirmation of the original expectation has an effect on satisfaction $[61,62$, 64]. Ryan et al. [63] found that user expectations affected satisfaction with EHR system yet was moderated by experience.

Disconfirmation to the providers' initial expectation EMR system has a negative effect on the level of satisfaction with the EMR was found by Ayanso et al. [64]. Therefore, in the context of health information quality, it is proposed: 
$H_{3}$ : Post-adoption disconfirmation of the initial information quality expectations is positively associated with healthcare providers' satisfaction with the EHR system in terms of information quality.

Workarounds have a variety of definitions in the IS literature, but the common theme is the action taken to overcome an obstacle to achieve a goal. Patient safety is of utmost importance in healthcare, and workflow exceptions, dysfunctional system features, regulatory requirements (among other triggers) may call for providers to work around to standardized workflow and processes [66] but risk harm to patients [68]. Workarounds in the healthcare domain are considered an act of resilience, a means to overcome difficulties [69], and to provide a means to deliver service in a more efficient way [70]. The additional work tasks, which are mainly clerical, imposed by EHR systems also may trigger workarounds. In terms of information quality, if the EHR system falls short in delivering the expected information and providers are not satisfied with the system, providers may create a workaround by searching elsewhere, such as in legacy systems, ask for records from other providers, or use paper records. Lower satisfaction with and IS triggers workaround to avoid using and IS [71] to level out the satisfaction, as found among healthcare providers [72,73] . Therefore, it is proposed:

$H_{4}$ : Post-adoption satisfaction with an EHR system in terms of information quality will be negatively associated with workarounds to overcome postadoption dissatisfaction.

\section{Research methods}

This study was designed to test the above hypotheses in two phases following Venkatesh and Davis' data collection methodology [19]. In the first phase, the initially formed expectations in regard to the four dimensions of information quality were measured prior to use of a newly implemented EHR system but after the initial training. In the second phase, the disconfirmation effect of the initial EIQ was measured two months after the EHR system was used for part or all of the providers' job functions. The initial survey took about 15 minutes to complete and requested the respondent to indicate his or her level of expectations of the new EHR system's ability to provide certain information quality attributes that were required for performance of their daily job duties. The second phase took about a half hour to complete and requested the respondent to disconfirm their expectations on the initial EIQ post EHR implementation and two months of use to perform at least part of their daily job duties using the EHR system. This involved measurement of the level of satisfaction with the new EHR system in terms of quality information provided post implementation. Additional items concerned whether users felt the need to work around the EHR system to input or retrieve information due to certain shortcomings of the EHR system's ability to provide or capture the information in the format needed.

Participants, who were recruited on a voluntary basis, were from a research hospital where a new EHR system had been implemented. A pretest of the questionnaires was conducted by IS experts and a representative of the steering committee in the hospital. The steering committee agreed to assist with the research and helped to recruit volunteers. A total of 92 providers, including physicians and nurses from multiple departments, enrolled in the study, and 64 respondents completed both phases. The questionnaires were administered through a paper copy to ensure the participants' anonymity.

The instruments used established measurement items, each of which was answered on a 7-point Likert scale. Information quality items were adopted from Lee et al. [30] and Wang \& Strong [44], and wording was adopted from McKinney et al. [74]. Each information quality attribute item began as follows: "Based on my experience so far, I expect that the EHR system will ... ," and a response was, “. . . present sufficiently complete information for my needs to perform my job duties." There were 12 reverse-coded questions; for example: “ . . . present incomplete information for my needs to perform my job duties" [30]. All EIQ dimensions were properly defined, and an example from the medical field was provided where applicable. A total 34 items were used for the four EIQ dimensions, after eight items were removed based on exploratory factor analysis. Responses ranged from $1=I$ completely disagree to $7=$ I completely agree .

Testing the disconfirmation of EIQ involved a reworded version of the 34 EIQ items, and all questions began with, "Compared to my initial expectations, the ability of the EHR system ....," and a sample response was "... to present sufficiently complete information for my needs to perform my job duties was . . ." Responses ranged from $1=$ much worse than I expected to $7=$ much better than I expected [75].

The satisfaction measures were adopted from Seddon and Yip [76] and from Delone and McLean [28]. Twelve items were used to measure user satisfaction with the EHR system use after the first two months in terms of information quality provided. The questions were proceeded by "Based on your experience so far, lease rate your satisfaction level with the new EHR system in terms of following:" and a sample question from satisfaction measurement: "Availability of information" or "credibility of information". 
Responses ranged from $1=I$ am extremely dissatisfied to $7=$ I am extremely satisfied.

Workaround items on the questionnaire followed up on the twelve satisfaction questions and asked the participants to disclose the workaround they may have performed due to dissatisfaction with the EHR system in terms of certain information quality attribute. Questions were preceded by "During my experience with the EHR system, I did my work differently, at least once, than expected from me in order to perform my job duties, because:..." and example questions were "...I did not have access to the information necessary" or "...the information was not presented consistently in the same format". Responses ranged from 1 = I completely disagree to 7 = I completely agree.

Workaround measurement items are not available in the literature that measure workaround based on satisfaction with information quality. The measurement items were derived from the literature $[77,78]$ but had to be reworded substantially.

The procedure for the study followed that of Bhattacherjee and Premkumar [53] in a longitudinal setting. The initial training provided respondents with enough knowledge of the EHR system to form an expectation about the information quality needed to perform their job functions.

\section{Results}

After the measurement items were identified, exploratory factor analysis was used to assess item quality. Principle component analysis with direct oblimin rotation revealed four factors with an eigenvalue greater than 1 and explained $76 \%$ of the total variance. A scree test also indicated four factors [79]. Eight information quality measurement items that loaded at less than 0.60 and had greater than 0.30 crossloadings were removed. Internal consistency reliabilities (ICRs) were over 0.80. Discriminant validity, a check to ensure that constructs are different from each other, was measured by the average variance extracted (AVE), and all items were above the 0.50 standard. Each construct exhibited a higher square root of the AVE than did the correlation of other constructs [80], which further demonstrated sound discriminant validity. The composite reliability, the measure of internal consistency of each indicator with its construct, was over 0.90 . The results confirmed convergent validity of the model.

\subsection{Measurement model}

The research model developed in this study employed structural equation modeling (SEM) based on partial least squares (PLS) to test the explanatory character of the model based on the theoretical background. The literature recommends PLS over covariance-based SEM (CBSEM), such as maximum likelihood (ML) estimation [81]. PLS is a better fit for prediction when hypotheses are derived from a general theory that does not recognize all relevant variables, making the theory is less sound [91]. CBSEM provides a better fit for the purpose of theory confirmation.

The measurement was created in structural equating software, SmartPLS (v.3.2.6), to assess the properties of the latent constructs. Sample covariance matrices were utilized to test the explanatory power and overall fit of the research model and, ultimately, the relative strengths of the causal paths between the variables described in the model. Common model-fit measures were used to evaluate the model's goodness-of-fit, and all measures were within the tolerance limits found in the literature, as shown in parentheses. Non-normed fit index (NNFI): 0.934 (>0.90), comparative fit index (CFI): 0.961 $(>0.90)$, root mean square error of approximation (RMSEA): $0.059(<0.10)$, normed chi-square: 2.18 $(<3.0)$, GFI: $0.973(>0.90)$.

\subsection{Structural model}

SPSS statistical software (v. 21) was used to test the structural model for collinearity. The variance inflation factor (VIF - 1/(1-R $\left.{ }^{2}\right)$ ) was below 10 [82] and indicated that multicollinearity was not a problem. A bootstrap method was used to calculate standard errors and the constructs' $t$-values to evaluate the structural relationships and properties of the latent variables [83]. The construct EIQ to SA obtained a positive coefficient of 0.282 and a $t$-value of $2.211(p<0.05)$, supporting H1. EIQ to DC presented a negative coefficient of 0.136 with a $t$-value of $3.537(p<0.01)$, supporting $\mathrm{H} 2$. DC to SA obtained a positive coefficient of 0.189 and a $t$-value of $0.097(p=0.43)$ and did not support H3. SA explained $29.4 \%$ of variance $\left(R^{2}=0.294\right)$, and a blindfolding method was used to verify Stone-Geisser's predictive relevance $\left(Q^{2}\right)$ as suggested by Hair et al. [84]. SA to WA obtained a negative coefficient of 0.389 and a $t$-value of $4.489(p<0.01)$ and explained $39.3 \%$ of the variance $\left(R^{2}=0.393\right)$.

\begin{tabular}{llll}
\hline Hypotheses & $\begin{array}{l}\text { Path } \\
\text { coeficient }\end{array}$ & T-value & p-value \\
\hline H1 Supported & 0.282 & 2.211 & $<0.05$ \\
H2 Supported & -0.136 & 3.537 & $<0.01$ \\
H3 Not Supported & 0.189 & 0.097 & 0.43 \\
H4 Supported & 0.389 & 4.489 & $<0.01$ \\
\hline
\end{tabular}

Table 2. Path coefficients in the structural model 


\section{Discussion and contributions}

The purpose of this study was to develop a model that helps to explain healthcare providers' information quality expectation from an EHR system, how a disconfirmed expectation shapes their satisfaction with the system, and the impact of satisfaction on EHR system workarounds. The rich literature provided theoretical grounding for the model, which was empirically tested.

The positive and significant relationship between pre-use EIQ and SA indicates that perceived information quality across all four dimensions of information (intrinsic, contextual, representational, accessibility) is a significant driver of providers' perceived satisfaction with the EHR system. The low variance explained (29.4\%) may be due to the fact that a variable other than information quality drives satisfaction. EHR is a complex system with multiple functions and thus, usability, security, and other system characteristics were outside of the scope of this study and have been found to be drivers of user satisfaction [89].

The negative and significant relationship between pre-use EIQ and DC indicates that the expected information quality across all four dimensions was higher than the post-adoption and use perception. A possible explanation is that EHR system implementations are preceded with provider "buy-ins" and "onboarding," which often result in glorifying the upcoming system. Although users, especially older physicians, have a natural resistance to technical changes that are inevitable during an EHR system implementation [90], the pre-implementation discussion may inflate expectations to reduce initial resistance and increase morale about the implementation. It may be that the usability and administration concerns are alleviated by providing better access to more comprehensive patient data, which may inflate the expectations.

The non-significant relationship between DC and SA may be explained by the many other factors that drive satisfaction with an EHR system in terms of information quality. Although relevant and timely data is important, usability and the increased amount of time required to enter notes may be more appropriate indicators of satisfaction.

The largest negative effect across the four hypotheses was between satisfaction and workarounds of the EHR system to overcome post-adoption dissatisfaction with information quality and is in line of previous studies [86,87]. The literature includes numerous factors that drive workaround decisions, with treating patients in a timely manner as a major determining factor $[39,85]$. This result suggests that providers may not want to rely only on data in the EHR system and will do whatever it takes to get the right information to make decisions and treat patients. The increased explanatory power $(39.3 \%)$ suggests that workarounds are due, to a large extent, to dissatisfaction with the quality of information that the EHR system takes or provides across all four dimensions of information quality. When providers feel dissatisfied with the EHR system's ability to provide or capture quality information related to patient care, they are more likely to work around the system to capture or acquire the needed information.

This study contributes to the workaround literature in the healthcare industry. Although many factors that trigger workarounds have been identified, there is limited research on what causes a workaround in an EHR system in terms of information quality expectations. An initial set of quantitative measures was proposed in this study and includes the 11 types of workarounds described in Alter's theory of workarounds [24] in an information quality domain. The workaround literature is mostly qualitative, but this study approached the triggers and effects quantitatively. The widely used technology acceptance models may incorporate workarounds into the use behavior outcome variable, as usage of a system can vary greatly, depending on the degree to which the expectations for the systems are met.

The findings also may serve as an indicator to management to deliver realistic expectations in regard to an upcoming EHR system implementation. Software providers also may benefit from an understanding of pre-acceptance expectations in regard to a variety of system characteristics. When an EHR system upgrade occurs, the model may be beneficial to determining how to reduce or prevent workarounds.

\section{Limitations and directions for further research}

This study has several limitations. First, the small sample size may decrease the power of the findings. Second, the generalizability is limited, as data were collected from one hospital implementing a certified EHR system, and the training and other preimplementation "onboarding" methods may be unique and skew the results. Third, the information quality dimensions may reveal more specific and granular results if measured as separate formative dimensions of the EIQ latent construct. Furthermore, if the importance of each EIQ category are measured, the study could pinpoint the gaps between expected information quality and the satisfaction with it. It would be interesting to measure the relation between the significance of information category and the expectation-satisfaction gaps across stakeholders using the EHR system. Fourth, 
expectations of other system characteristics, such as usability and security, may provide a better understanding of where and how workarounds are triggered. Fifth, the study used the simplified expectation-conformation model without performance. With proper measures, an understanding of performance in relation to original expectations may pinpoint user inabilities as opposed to perceived system shortcomings. It is recommended to compare the findings with process-mining results and to explore in which steps users deviate from the organizational processes and expected workflows.

Final recommendation for future studies is to explore the effect of workaround as a mediator on satisfaction. Literature indicates that fixing problems and working around rules in the sake of patient care enhances perceived personal proficiency [73] and confidence in their competence [88], and in turn may affect the satisfaction with the system as reduces frustration and stress [39] and workarounds were found to increase healthcare employee's over satisfaction with EHR systems [91].

\section{References}

[1] Tang, PC et al. "Comparison of Methodologies for Calculating Quality Measures Based on Administrative Data versus Clinical Data from an Electronic Health Record System: Implications for Performance Measures." J Am Med Inform Assoc., 14(1), 2007, pp. 10-15.

[2] Nguyen, L, Bellucci, E, Nguyen, LT. "Electronic health records implementation: An evaluation of information system impact and contingency factors", Int J Med Inform, 83(11), 2014, pp. 779-96.

[3] Office of the National Coordinator for Health Information Technology (ONC) Department of Health and Human Services. 2014 Edition Electronic Health Record certification criteria: revision to the definition of "common meaningful use (MU) data set" Fed Regist, 45(65), 2013, pp. 884-7.

[4] Oliveira,S.V.W., Arroy,C.S., Oliveira, M.M., Freira. A. H. "Use and development of health information systems: the experience of an organizational unit responsible for the technological services at a public hospital", Journal of Information Systems and Technology Management, 8(1), 2011, pp. 155-178.

[5] ISO/DTR 20514, Health Informatics - Electronic Health Record - Definition, Scope, and Context, 2004.

[6] Okkes, I.M., Groen, A., Oskam, S.K., and Lamberts, H. "Advantages of long observation in episode-oriented electronic patient records in family practice", Meth. Inf. Med. 40(3), 2001, pp. 229-235.

[7] Dick, R.S., Steen, E.B., Detmer, D.E. (eds). The ComputerBased Patient Record: An Essential Technology for Health Care, Washington, DC: National Academy Press, 1997.

[8] Davies EC, Green CF, Mottram DR, et al. "Emergency readmissions to hospital due to adverse drug reactions within 1 year of the index admission”, Br J Clin Pharmacol., 70(5), 2010, pp.749-55.
[9] Shadmi E, Flaks-Manov N, Hoshen M, Goldman O, Bitterman H, Balicer RD. "Predicting 30-day readmissions with preadmission electronic health record data", Medical Care, 53(3), 2015, pp. 283-9.

[10] Koppel R, Wetterneck T, Telles JL, Karsh BT. "Workarounds to barcode medication administration systems: their occurrences, causes, and threats to patient safety", $J \mathrm{Am}$ Med Inform Assoc., 15(4), 2008, pp. 408-423.

[11] Azad, B., King, N. "Enacting computer workaround practices within a medication dispensing system", European Journal of Information Systems, 17(3), 2008, pp. 264-278.

[12] Patterson, ES, Rogers, ML, Chapman, RJ, Render, ML. "Compliance with intended use of bar code medication administration in acute and long-term care: an observational study", Hum Factors, 48(1), 2006, pp. 15-22

[13] Carayon, P. Handbook of Human Factors and Ergonomics in Health Care and Patient Safety. 2007, Mahwah: Lawrence Erlbaum Associates

[14] Hakimzada AF, Green RA, Sayan OR, Zhang J, Patel VL. "The nature and occurrence of registration errors in the emergency department”, Int J Med Inf., 77(3), 2008, pp. 169175 .

[15] Zhang, P., Dran, G. "Expectations and ranking of website quality features: results of two studies on user perceptions", In: Proceedings of the 34th Hawaii International Conference on System Sciences. 2001.

[16] Castillo, V., Martinez-Garcia, A., \& Pulido, J. "A knowledge-based taxonomy of critical factors for adopting electronic health record systems by physicians: A systematic literature review", BMC Medical Informatics and Decision Making, 10(60), 2010, pp. 1-17.

[17] McGinn, C., Grenier, S., Duplantie, J., Shaw, N., Sicotte, C., Mathieu, L., Leduc, Y., Legare, F., \& Gagnon, M. "Comparison of user groups' perspectives of barriers and facilitators to implementing electronic health records: A systematic review", BMC Medicine, 9(46), 2011, pp. 1-10.

[18] Menke, J.A., Broner, C.W., Campbell, D.Y., McKissick, M.Y., and Edwards-Beckett, J.A. "Computerized clinical documentation system in the pediatric intensive care unit”, BMC Med. Inf. Decis. Mak., 1(3), 2001, Epub.

[19] Venkatesh, V., \& Davis, F. D. "A theoretical extension of the technology acceptance model: four longitudinal field studies", Management Science, 46(2), 2000, pp. 186-204.

[20] Venkatesh, V., Morris, M. G., Davis, G. B., \& Davis, F. D. "User acceptance of information technology: toward a unified view", MIS Quarterly, 27(3), 2003, pp. 425-478.

[21] Davis, F. D. "Perceived usefulness, perceived ease of use, and user acceptance of information technology", MIS Quarterly, 13(3), 1989, pp. 319-340.

[22] Davis, F. D., Bagozzi, R., \& Warshaw, P. R. "User acceptance of computer technology: a comparison of two theoretical models", Management Science, 35(8), 1989, pp. 982-1003.

[23] Alter, S. The Work System Method: Connecting People, Processes, and IT for Business Results, Larkspur, CA: Work System Press. 2006.

[24] DeLone, W. H., McLean, E. R. "Information systems success: the quest for the dependent variable". Information systems research, 3(1), 1992, pp. 60-95.

[25] Oliver, R. L. "Effect of expectation and disconfirmation on postexposure product evaluations: An alternative 
interpretation." Journal of Applied Psychology, 62(4), 1977, pp. 480-486.

[26] Alter, S. "Theory of Workarounds", Communications of the Association for Information Systems, 34(1), 2014, pp. 1041-1066.

[27] DeLone, W.H., and McLean, E.R. "Information Systems Success Revisited," in: Proceedings of the 35th Hawaii International Conference on System Sciences (HICSS 02). Big Island, Hawaii: pp. 238-249. 2002.

[28] DeLone, W.H., and McLean, E.R. "The DeLone and McLean Model of Information Systems Success: A Ten-Year Update," Journal of Management Information Systems 19(4), 2003, pp. 9-30.

[29] Bailey, J. E., and Pearson, S. W., "Development of a Tool for Measuring and Analyzing Computer User Satisfaction", Management Science, 29(5), 1983, pp. 530-545.

[30] Lee, Y. W., Strong, D. M., Kahn, B. K., Andwang, R. Y., "AIMQ: A methodology for information quality assessment", Information \& Management, 40(2), 2002, pp. 133-460.

[31] Oliver, R. L., "Cognitive, Affective, and Attribute Bases of the Satisfaction Response", Journal of Consumer Research, 20(3), 1993, pp. 418-430.

[32] Oliver, R. L. "A Cognitive Model for the Antecedents and Consequences of Satisfaction", Journal of Marketing Research 17(4), 1980, pp. 460-469.

[33] Oliver, Richard L. Satisfaction: A Behavioural Perspective on the Consumer, New York: McGraw Hill. 1997.

[34] Alter, S. "A Workaround Design System for Anticipating, Designing, and/or Preventing Workarounds," EMMSAD 2015 (Exploring Modeling Methods for Systems Analysis and Design) a working conference associated with CAISE 2015 (Conference on Advanced Information System Engineering), June 8-12, Stockholm, Sweden. 2015.

[35] Schoville RR: Work-arounds and artifacts during transition to a computer physician order entry: what they are and what they mean. J Nurs Care Qual. 2009, 24 (4): 316-324. [36] Varpio L, Schryer CF, Lehoux P, Lingard L: Working off the record: physicians' and nurses' transformations of electronic patient record-based patient information. Acad Med. 2006, 81 (10): S35-S39.

[37] Lopez KD, Gerling GJ, Cary MP, Kanak MF: Cognitive work analysis to evaluate the problem of patient falls in an inpatient setting. J Am Med Inform Assoc. 2010, 17 (3): 313 321.

[38] Kobayashi M, Fussell SR, Xiao Y, Seagull FJ: Work coordination, workflow, and workarounds in a medical context. Conference on Human Factors in Computing Systems: CHI '05. 2005, Portland, United States: Association for Computing Machinery, 1561-1564.

[39] Baker, H.M., "Rules outside the rules for administration of medication: a study in New South Wales", Australia. J Nurs Scholarsh., 29(2), 1997, pp. 155-158.

[40] Eisenhauer LA, Hurley AC, Dolan N, Eisenhauer LA, Hurley AC, Dolan N. "Nurses' reported thinking during medication administration", J Nurs Scholarsh, 39(1), 2007, pp. 82-87.

[41] Koppel, R., Wetterneck, T., Telles, J.L., Karsh, B.T., "Workarounds to barcode medication administration systems: their occurrences, causes, and threats to patient safety", $\mathrm{J} \mathrm{Am}$ Med Inform Assoc., 15(4), 2008, pp. 408-423.

[42] Niazkhani, Z., Pirnejad, H., van der Sijs, H., Aarts, J. "Evaluating the medication process in the context of $\mathrm{CPOE}$ use: the significance of working around the system", Int J Med Inf., 80(7), 2011, pp. 490-506.

[43] Saleem, J.J., Patterson, E.S., Militello, L., Render, M.L., Orshansky, G., Asch, S.M., "Exploring barriers and facilitators to the use of computerized clinical reminders", $J$ Am Med Inform Assoc., 12(4), 2005, pp. 438-447.

[44] Wang, R. and Strong, D., "Beyond accuracy: What data quality means to data consumers", Journal of Management Information Systems, 12(4), 1996, pp. 5-33.

[45] Wixom, B. H., and Todd, P. A., "A theoretical integration of user satisfaction and technology acceptance", Information Systems Research, 16(1), 2005, pp. 85-102.

[46] Xu, J. J., Benbasat, I. and Cenfetelli, R. T., "Integrating service quality with system and information quality: an empirical test in the e-service context", MIS Quarterly, 37(3), 2013, pp. 777-794.

[47] Au, N., Ngai, E. W. T., and Cheng, T. C. E., "Extending the understanding of end user information systems satisfaction formation: An equitable needs fulfillment model approach", MIS Quarterly, 32(1), 2008, pp. 43-66.

[48] Otieno OG, Toyama H, Asonuma M, Kanai-Pak M, Naitoh K. Nurses' views on the use, quality and user satisfaction with electronic medical records: questionnaire development. J Adv Nurs. 2007 Oct;60(2):209-19.

[49] R. J. Koopman, L. M. B. Steege, J. L. Moore, M. A. Clarke, S. M. Canfield, M. S. Kim, J. L. Belden. Physician Information Needs and Electronic Health Records (EHRs): Time to Reengineer the Clinic Note. The Journal of the American Board of Family Medicine, 2015; 28 (3): 316-323. [50] Terry AL, Thorpe CF, Giles G, Brown JB, Harris SB, Reid GJ, Thind A, Stewart M, "Implementing electronic health records", Canadian Family Physician, 54 (5), 2008, pp. 730-736.

[51] Miller RH, Sim I, 'Physicians' Use of Electronic Medical Records: Barriers and Solutions", Health Affairs, 23(2), 2004, pp. 116-126.

[52] Ebell MH, Frame P. "What can technology do to, and for, family medicine?", Family Medicine, 33(4), 2001, pp. 311-9.

[53] Bhattacherjee, A., Premkumar, G., "Understanding changes in belief and attitude toward information technology usage: A theoretical model and longitudinal test", MIS Quarterly, 28(2), 2004, pp. 351- 370.

[54] Yi, Y., A critical review of consumer satisfaction. V. A. Zeithaml, ed. Review of Marketing. American Marketing Association, Chicago, IL, 1990, pp. 68-123.

[55] Bhattacherjee, A., "Understanding information systems continuance: An expectation confirmation model", MIS Quarterly, 25(3), 2001, pp. 351-370.

[56] Bhattacherjee, A., "An empirical analysis of the antecedents of electronic commerce service continuance", Decision Support Systems, 32(2), 2001, pp. 201-214.

[57] Hsu, M. H., C. M. Chiu, T. L. Ju. "Determinants of continued use of the WWW: An integration of two theoretical models", Industrial Management \& Data Systems, 104(9), 2004, pp. 766-775.

[58] Spreng R, Olshavsky R.A. "Desire-as-standard model of consumer satisfaction", Journal of Consumer Satisfaction, Dissatisfaction and Complaining Behaviour, 5, 1992, pp. 4554.

Page 3047 
[59] Spreng R, Olshavsky R. “A desires congruency model of consumer satisfaction. Journal of the Academy of Marketing Science", 21(3), 1993, pp. 169-77.

[60] Suh K, Kim S, Lee J. "End-user's discon4rmed expectations and the success of information systems", Information Resources Journal,7(4), 1994, pp. 31-9.

[61] Lawrence M, Low G. "Exploring individual user satisfaction within user-led development", MIS Quarterly, 17(2), 1993, pp. $195-208$.

[62] Ryker R, Nath R, Henson J. "Determinants of computer user expectations and their relationships with user satisfaction: an empirical study" Information Processing and Management, 33(4), 1997, pp. 529-37.

[63] O`Connell RT, Cho C, Shah N, Brown K, Shiffman RN. "Take note(s): differential EHR satisfaction with two implementations under one roof", Journal of the American Medical Informatics Association, 11(1), 2004, pp. 43-49.

[64] Yoon, S.-J., \& Kim, J.-H. "An empirical validation of a model based on expectation disconfirmation", Journal of Consumer Marketing, 17(2), 2000, pp. 120-136.

[65] Anteneh, A, Herath, TC, O'Brien, N. "Understanding Continuance Intentions of Physicians with Electronic Medical Records (EMR): An Expectancy-Confirmation Perspective", Decision Support Systems, 77, 2015, pp. 112 122.

[66] Koppel R, Wetterneck T, Telles JL, Karsh B-T. "Workarounds to barcode medication administration systems: their occurrences, causes, and threats to patient safety", $J \mathrm{Am}$ Med Inform Assoc. 15(4), 2008, pp. 408-423.

[67] Whooley, O. "Diagnostic ambivalence: psychiatric workarounds and the diagnostic and statistical manual of mental disorders", Sociol Health Illn, 32(3), 2010, pp. 452469.

[68] Whooley, O. "Diagnostic ambivalence: psychiatric workarounds and the diagnostic and statistical manual of mental disorders", Sociol Health Illn, 32(3), 2010, pp. 452469.

[69] Hollnagel E, Woods D, Leveson N. "Resilience Engineering Concepts and Precepts", Aldershot: Ashgate Publishing Limited. 2006.

[70] Lalley C, Malloch K. "Workarounds: the hidden pathway to excellence", Nurse Leader, 8(4), 2010, pp. 29-32.

[71] Sven, L, Maier, C and Weitzel. T. "Information quality, user satisfaction, and the manifestation of workarounds: a qualitative and quantitative study of enterprise content management system users." European Journal of Information Systems, Epub, 2017, pp. 1-28.

[72] Hutchinson, SA. "Responsible subversion: a study of rule-bending among nurses", Res Theory Nurs Pract., 4(1), 1990, pp. 3-17.

[73] Tucker AL, Edmondson A: Why hospitals don't learn from failures: organizational and psychological dynamics that inhibit system change. Calif Manage Rev. 2003, 45 (1): 55-72. [74] McKinney, V., Yoon, K., \& Zahedi, F. M., "The measurement of Web-customer satisfaction: An expectation and disconfirmation approach", Information Systems Research, 13(3), 2002, pp. 296-315.

[75] Lankton, N., Mcknight, D., "Using expectation disconfirmation theory to predict technology trust and usage continuance intentions", Eli Broad College of Business, 2006.
[76] Seddon, P.B. \& Yip, S.K. "An empirical evaluation of user information satisfaction UIS, measures for use with general ledger accounting software", Journal of Information Systems, 6, 1992, pp. 75-92

[77] Wheeler AR, Halbesleben JRB, Harris KJ: How job-level HRM effectiveness influences employee intent to turnover and workarounds in hospitals. J Bus Res. 2012, 65 (4): 547-554.

[78] Nadhrah, N., Michell, V. Measuring Physicians Workarounds: Implications on Work Processes and Patient. In: Zhang R., Zhang Z., Liu K., Zhang J. (eds) LISS 2013. Springer, Berlin, Heidelberg, 2015.

[79] Cattell, R.B. (Ed.). Handbook of multivariate experimental psychology (2nd ed.). Chicago: Rand McNally. 1966.

[80] Chin, WW. "Issues and opinion on structural equation modeling"' MIS Quarterly, 22(1), 1998, pp. 7-16.

[81] Barroso, C., Carrión, G.C. and Roldán, J.L., Applying maximum likelihood and PLS on different sample sizes: studieson SERVQUAL model and employee behavior model, Handbook of Partial Least Squares, pp. 427-447, Springer Handbooks of Computational Statistics, Springer-Verlag, London, UK., 2010.

[82] Myers, R. Classical and Modern Regression with Applications. Duxbury Press, Boston, MA., 1990.

[83] Wetzels, M., G. Odekerken-Schroder, and C. Van Oppen, "Using PLS path modeling for assessing hierarchical construct models: guidelines and empirical illustration", MIS Quarterly, 33(1), 2009, pp. 177-195.

[84] Hair, J. F., Hult, G. T. M., Ringle, C. M., and Sarstedt, M., A Primer on Partial Least Squares Structural Equation Modeling (PLS-SEM), Sage: Thousand Oaks, CA, 2014.

[85] Schoville, R.R. "Work-arounds and artifacts during transition to a computer physician order entry: what they are and what they mean", J Nurs Care Qual., 24(4), 2009, pp. 316324.

[86] Koppel R, Wetterneck T, Telles JL, et al. "Workarounds to barcode medication administration systems: their occurrences, causes, and threats to patient safety", Journal of the American Medical Informatics Association, 15, 2008, pp. 408-23.

[87] Vogelsmeier AA, Halbesleben JRB, Scott-Cawiezell JR. "Technology implementation and workarounds in the nursing home", Journal of the American Medical Informatics Association, 15, 2008, pp. 114-19.

[88] Tucker, AL, Edmondson, A., Spear, S. "When problem solving prevents organizational learning", J Organisational Change Manage, 15(2), 2002, pp. 122-136.

[89] Yen, P.-Y., \& Bakken, S. (2012). Review of health information technology usability 55 study methodologies. Journal of the American Medical Informatics Association, 19(3), 413-422.

[90] Decker SL, Jamoom EW, Sisk JE. "Physicians in nonprimary care and small practices and those age 55 and older lag in adopting electronic health record systems" Health Affairs, 31(5), 2012, pp. 1108-1114. [91] Barrett, AK., Stephens, KK. "Making Electronic Health Records (EHRs) Work: Informal Talk and Workarounds in Healthcare Organizations", Health Communication, 32(8), 2017, pp. 1004-1013. 